\title{
A STUDY ON THE COMPLETENESS, FINITE VERB TENSE, AND VOICE OF COCONUT RESEARCH ABSTRACTS
}

\author{
Muhartoyo \\ English Department, Faculty of Humanities, Bina Nusantara University \\ Jl. KemanggisanIlir III no.45, Kemanggisan/Palmerah, Jakarta Barat 11480 \\ ymuhartoyo@yahoo.com
}

Received: $1^{\text {st }}$ March 2016/ Revised: $1^{\text {st }}$ April 2016/ Accepted: $20^{\text {th }}$ April 2016

How to Cite: Muhartoyo. (2016). A Study on the Completeness, Finite Verb Tense, and Voice

of Coconut Research Abstracts. Lingua Cultura, 10(1), 49-55.

http://dx.doi.org/10.21512/lc.v10i1.879

\begin{abstract}
Abstract is a secondary source of scientific information which can help scientists to get the gist of relevant information needed for their study. Scientific article usually provides informative abstracts to facilitate readers to know the essential content of the article. The quality of an abstract depends on the accuracy and completeness of abstract components or elements. This research was intended to find out the completeness of abstract elements, finite verb tenses, and the voice of coconut research abstracts. A total of 34 abstracts from the last three-year issues of CORD journal were analyzed. The result of the analysis showed that there were two categories i.e. indicative abstracts (21\%) and comprehensives abstracts (79\%). The most complete informative abstracts consisting of 5 elements accounted for $23 \%$, the informative abstracts with four elements had the highest amount which was $41 \%$, and the informative/comprehensive abstracts with three elements had the least amount which is $15 \%$. It can be concluded that most informative/ comprehensive abstracts contain four elements which are background (introduction), objectives, methodology, and result. Four tenses are usually used in abstract writing; they are simple present, simple past, present and past perfect tense. Both active and passive voices are used in writing abstracts.
\end{abstract}

Keywords: indicative abstract, informative abstracts, finite verbs, active voice, passive voice

\section{INTRODUCTION}

Scientific communication is an essential part of research and development. This type of communication is usually carried out through publications. Both paper-based and on-line scientific publications play equally important roles in keeping the flow of information exchange among scientists. The important role of scientific publications is signified by the number of research articles published in various international, peer-reviewed journals. According to Ware and Mabe (2012), the annual published scientific articles around the world reach 1.8 million titles. To keep up with this huge number of scientific publications, scientists should keep themselves updated with the latest development of their disciplines. It is highly unlikely to read all those scientific publications, besides too costly it will be too time-consuming. One of the easier ways that can be taken by scientists to keep themselves updated is by subscribing abstracts of relevant publications.

An abstract is a representation of a larger work in the form of a self-contained, short, and powerful statement. The components of abstracts vary depending on discipline. For a social science or scientific work, the abstracts may comprise of the scope, purpose, results, and contents of the work. For a humanities work, the abstract may include the thesis, background, and conclusion of the larger work. It should be noted that an abstract is neither a review nor an evaluation of the work being abstracted. While it contains keywords found in the larger work, the abstract is an original document rather than an excerpted passage.

Bailey (2011) has described briefly that abstract is usually located at the beginning of peer-reviewed journal articles. The function of abstract is giving a kind of summary so that researchers can decide if the full article is worth reading. Abstracts consist of Background position, Aim and thesis of the article, Method of research, and Result of research.

According to the University of North Carolina (UNC) abstracts are generally categorized into two different categories i.e. descriptive and informative abstracts. A descriptive abstract indicates the type of information found in the work. It makes no judgments about the work, nor does it provide results or conclusions of the research. It does incorporate keywords found in the text and may include the purpose, methods, and scope of the research. The term 'descriptive abstract' is interchangeable with 'indicative abstract'. 
This kind of abstract can be used to represent a lessstructured document like essay, editorial, or book. Indicative abstracts may cover three elements: scope, argument, and conclusion. The first element is used to explain the coverage and the main focus of the original document. For example, an essay on Shakespeare's comedy, the Scope element of this abstract will state that the focus of the easy is on the Bard's comedies.Essentially, the descriptive abstract describes the work being abstracted. Meanwhile, the Argument element of the abstract will describe the primary arguments and counter-arguments contained in the essay (original document). If arguments and counter-arguments do not exist in the original document, this element of the indicative abstract will outline analysis or plot progression. Some people consider it an outline of the work, rather than a summary. Descriptive abstracts are usually very short -100 words or less.

Being the representation of the original documents (research papers, books, theses, dissertations, and articles) abstracts should be written accurately. It means what is stated in the abstract is coherent with what it is stated in the original documents. Discrepancies in abstract writing will mislead the potential readers of the original documents.

The majority of abstracts included in the scientific documents are informative. While they still do not critique or evaluate work, they provide concise and comprehensive information. A good informative abstract acts as a surrogate for the work itself. That is, the writer presents and explains all the main arguments and the important results and evidence in the complete article/paper/book. An informative abstract includes the information that can be found in a descriptive abstract (purpose, methods, and scope) but also includes the results and conclusions of the research and the recommendations of the author. The length varies according to discipline, but an informative abstract is rarely more than $10 \%$ of the length of the entire work. In the case of a longer work, it may be much less (UNC, 2014). Birmingham City University (BCU) has given a complete component of informative abstracts; they are background, $\operatorname{aim}(\mathrm{s})$, methods, results, and conclusions (BCU, 2015). The later will be used as the basis of analyzing the completeness of abstract components in this study.

The accuracy of information contained in abstracts is quite instrumental for potential readers to get unbiased information. Biased information of the abstracts may lead to incorrect understanding for the readers. According to the results of a study published in PLOS Medicine the "exaggerated and inappropriate coverage of research findings in the news media" is ultimately related to inaccurately reporting or over-interpreting research results in many abstract conclusions. A study published in JAMA concluded that "inconsistencies in data between abstract and body and reporting of data and other information solely in the abstract are relatively common and that a simple educational intervention directed to the author is ineffective in reducing that frequency. Other studies comparing the accuracy of information reported in a journal abstract with that reported in the text of the full publication have found claims that are inconsistent with, or missing from, the body of the full article (Pitkinet. al., 1999).

As previously mentioned abstracts are parts of scientific journal articles, they should be written based on academic writing standard which includes the target reader, content, style, organization, grammar, and vocabulary. The target reader is academics; the content contains serious thought, the style of writing uses complex sentences showing considerable variety in construction. The organization is clear and well planned and is likely to be error free in grammar. It tends to use accurate technical and academic language. Passive voice, the objective and impersonal point of view are more frequently used in academic writing (Hamp-Lyons, 2010).

\section{METHODS}

The purpose of this study is to evaluate the accuracy of coconut research abstracts compared to the original documents or articles. It will also look into finite verb tenses and voices in various components of the abstracts.

The data for this study are derived from CORD, an international journal of coconut research and development. The abstracts of scientific articles published in CORD for the period of last three years (2012-2014) were selected and analyzed. A total of 34 abstracts were collected from 35 scientific articles. Those abstracts were selected because they were published in the most recent issues of the journal at the time of data selection process. The analysis includes the completeness of abstract components, accuracy of the information, voice and finite verb tenses used in the abstracts.

CORD is an International Journal on Coconut Research and Development published by Asian and Pacific Coconut Community since 1985 . This journal is widely circulated among coconut researchers all over the world. All articles published in this journal have been scrutinized by members of the Editorial Board who are prominent experts from Indonesia, Philippines, India, Sri Lanka, Thailand, Australia, and the USA.

Most articles published in this journal present research results conducted by scientists from various countries including Indonesia, Malaysia, Thailand, Philippines, India, Sri Lanka, Australia, and France. Occasionally some review articles by prominent experts in the field were included in the publication.

As mentioned in section 2, there are 34 abstracts taken from the last three-year issues of the CORD journal which will be analyzed in this study. The abstracts were systematically numbered which began from the latest issue of the journal (Vol. 30 No. 2, 2014). As indicated in the Introduction, most abstracts fall under the category of informative abstracts which contain full elements of abstracts as given by Birmingham City University and the University of North Carolina, such as background, aims, method, results, conclusion and recommendation. The analysis was focused on the identification of abstract elements. The analysis found seven abstracts that belong to indicative abstracts; they are abstracts no. 4, 12, 1,15, 22. As an example, abstract no 4 (Novarianto et al., 2014) is given.

\section{RESULTS AND DISCUSSIONS}

\section{4) Production Technology for Kopyor Coconut Seednuts and Seedlings in Indonesia}

\author{
Hengky Novarianto ${ }^{1}$, Ismail Maskromo ${ }^{1,2}$, \\ Dini Dinarti ${ }^{2}$, and Sudarsono ${ }^{2}$
}

\section{ABSTRACT}

Kopyor coconut is a naturally-occurring mutant having fluffy solid endosperm instead of the normal one. A similar type of coconut has been found in several other Asian countries, with 
their distinct local names, such as Macapuno (Philippines), Ma phraoKathi (Thailand), Dikiri Pol (Sri Lanka), Thairu Thengai (India). It is a delicacy coconut to Indonesian and sells as much as ten times higher than normal coconut. In nature, three types of kopyor coconut exist in Indonesia: kopyor tall, kopyor dwarf, and kopyor hybrid. There are three kopyor dwarf varieties ('PatiKopyor Green Dwarf', 'Kopyor Yellow Dwarf' and 'Kopyor Brown Dwarf') officially released, and one registered tall variety ('Puan Kalianda Kopyor Tall'). In general, kopyor fruit yield under natural conditions is only $<25 \%$ of the total harvested fruits for both the tall and the dwarf types. Traditionally, Indonesian farmers harvest kopyor fruits at ten months after pollination while normal fruits at 11 months. They use the harvested normal fruits for propagation but cannot guarantee whether or not they would produce korpyor fruit. Adoption of kopyor seedling production through embryo culture has been done. However, the seedling production is slow, while the price is very expensive, thus unaffordable to common farmers. Indonesian Palm Research Institute and Bogor Agricultural University have collaborated to develop alternative approaches to increase kopyor fruit production through the production of seedling that would ensure to produce korpyor fruit through control pollination. Initiated since 2010, the activities successfully overcome uncertainty in kopyor seedling production. Moreover, hybridization among local superior coconut varieties and known kopyor one have been done to broaden genetic background of kopyor trait and to develop breeding population for new kopyor varieties in the future. Overview and update of research progress on korpyor in Indonesia are presented in this paper.

Keywords: Coconut mutant, abnormal endosperm, controlled pollination, breeding population

The abstract only indicates the scope of the subject to be discussed without giving specific details of the research methodology and results. It does not provide conclusion and recommendation either. Therefore, this abstract is categorized as indicative or descriptive abstract.

The remaining 27 abstracts can be categorized into informative abstracts with various degrees of completeness. There are seven abstracts with complete five elements, 14 abstracts with four elements, and six abstracts with three elements. Abstract number 12 (Limphapayom, 2013) is an example of abstract containing five element $\mathrm{s}$.

12) Study on Chocolate Production from Coconut Oil and Palm Oil Shortening

Wilaisri Limphapayom

\section{ABSTRACT}

Chocolate is a well-known dessert all over the world. The original chocolate is made from cocoa products: cocoa bean and cocoa butter. Research and Development on the low-fat chocolate process were conducted for value addition of coconut oil and Thai fruit. This chocolate processing study composed of (1) coconut oil fractionation, (2) chocolate formulation and (3) shelf-life storage determination. Accordingly, fatty acids composition of the blend of coconut fat and palm oil shortening were determined. It was found that the said product composed of Caproic acid0. 47 $\pm 0.12 \%$, Caprylic acid $5.65 \pm 0.31 \%$, Capric acid $5.14 \pm 0.14 \%$, Lauric acid $42.56 \pm 0.28 \%$, Myristic acid $16.31 \pm 0.18 \%$, Stearic acid $14.55 \pm 0.13 \%$, Oleic acid $9.26 \pm 0.17 \%$, and Linoleic acid $2.16 \pm 0.35 \%$. The saturated fatty acids and unsaturated fatty acids found in this product were $88.57 \pm 0.14 \%$ and with $11.42 \pm 0.81 \%$, respectively. The range of melting point is $26^{\circ} \mathrm{C}-33^{\circ} \mathrm{C}$ and oxidative stability is 14.2 to 16.7 hours. The chocolate formula of pale and dark chocolate $1 \mathrm{~kg}$ composed of coconut fat, palm oil shortening, and lecithin as emulsifier in same amounts such as 250g, $100 \mathrm{~g}$, and $0.5 \mathrm{~g}$. However, icing sugar and defatted cocoa powder are in different amounts; the icing sugar in pale chocolate and dark chocolate is $350 \mathrm{~g}$ and $450 \mathrm{~g}$ while the defatted cocoa powder in pale chocolate and dark chocolate is $200 \mathrm{~g}$ and $300 \mathrm{~g}$, respectively. These chocolate products have physical properties similar to the chocolate products produced from cocoa butter. The shelf life of these products is three months.

Keywords: chocolate, fractionate coconut oil, medium chain fatty acids

The first sentence of the previous abstract above gives a background (introduction) which is element 1. Element 2 which is the aim or purpose of the Research is revealed in the second sentence. Next, research methodology (element 3) starts from the third sentence. The results (element 4) begin from "It was found that...". Finally, theconclusion (element 5) starts from "These chocolate products....."

The less comprehensive informative abstract is the one with four elements in it. The abstract no. 1(Karouw et. al., 2014) is an example of this abstract.

1) Fatty Acids Profile, Oxidative and Hydrolysis Stability of Virgin Coconut Oil and Palm Stearin Based Human Milk Fat Analog

Steivie Karouw, Suparmo, Pudji Hastuti, and TyasUtami

\section{ABSTRACT}

Value and the objectives of the research are to evaluate fatty acids profile, oxidative and hydrolysis stability of human milk fat (HMF) analog by using virgin coconut oil (VCO) and palm stearin as raw materials. The HMF analog was synthesized through enzymatic interesterification catalyzed by lipase from Rhizomucormiehei. The fatty acid profiles of interesterification products were monitored 
using gas chromatography. The oxidative stability test was carried out for up to 72 hours at $60^{\circ} \mathrm{C}$. The peroxide value was measured during 0, 24, 48 and 72 hours of storage duration. Hydrolysis stability test was held for up to 8 days at room temperature. The free fatty acid content was monitored during 0, 2, 4, 6 and eight days of storage. The results showed that the resulted HMF analog had a high percentage of palmitic acid in the sn-2 position, similar to that of HMF. The palmitic acid content in the sn-2 position was around $39.71 \%$. The MCFAs were esterified in the sn-1 and sn-3 position, and the main fatty acid constituent was lauric acid of $39.37 \%$. The obtained HMF analog was stable to oxidative and hydrolysis deterioration asindicated by the peroxide free fatty acid content during storage.

\section{Keywords: interesterification, gas, chromatography, peroxide value, lauric acid, palmitic acid}

Abstract number 1 starts with the aims or objectives (element 1) which begin with the first sentence. The second element which is the research methodology is given by the second sentence, while the third element is results, it begins from "The results showed..." This abstract does not mention either the research background/ introduction nor the conclusion.

The least comprehensive informative abstract in this study is the one with three elements in it as it can be seen in sample abstract number15 (Gallego et al., 2013).

15) Some Biological and Behavioral Studies of theTetrastichus sp.(Hymenoptera: Eulophidae), a Pupal Parasitoid of BrontispalongissimaGestro (Coleoptera: Chrysomelidae)

\author{
Vivencio C. Gallego, ma. Cynthia E. Gallego \\ and Ivorie J. dela Torre
}

\section{ABSTRACT}

The Tetrastichus sp. was identified as a pupal parasitoid indigenous to the Philippines. The total development period of Tetrastichus sp. from egg to adult was 16 days under laboratory conditions. The average incubation, larval and pupal periods were 3.5, 4.8, and 7.4 days, respectively. The average adult longevity was 5.5 (male) and 6.4 (female). Upon emergence of an adult wasp from the host pupa, mating took place shortly and the female look for suitable host pupa of Brontispalongissima for oviposition.Tetrastichus sp. is an endogregarious parasitoid. From one parasitized pupa of Brontispalongissima, around 6 - 66 individual wasps emerged with a mean of 22.4 while parasitized pupae collected from the field yielded 4-21 individuals with a mean of 12.7 . The majority of the wasps emerged in the morning (70\%) while 30\% emerged in the afternoon. The sex ratio of male and female was 1:5.4 in laboratory condition while 1:3.7 under field condition with females outnumbered the males. Tetrastichus sp. was observed in some cases to reproduce parthenogenetically. Longevity of Tetrastichus sp. can be enhanced to a mean of 7.3 and 6.0 days by feeding on sugar and honey, respectively while water and coconut pollen resulted in the longevity of 3.3 and 2.4 days, respectively. Adults without food lived only one day. Parasitism efficiency ratio of 10 parasitoids: 10 host pupae resulted in 90\% parasitism. One to two-day old pupa of $B$. longissima was preferred by Tetrastichus sp. for oviposition with a mean of $86.7 \%$ parasitism. Percent pupal parasitism in the field ranged $25.7-42.3 \%$ with an average of $27.6 \%$ in selected areas in Mindanao. Tetrastichus sp. was found to control B. longissima effectively under field condition. The study indicated that Tetrastichus sp. is an effective control agent of $B$. longissima and could be used in the field to prevent economic damage of the palms by the pest.

Keywords: Behavior, biology, biological control, Brontispalongissima, Parasitism, Tetrastichus sp.

The first element in the sample abstract no. 15 begins with the background of the research which is given in the first sentence of the abstract. After background, the second sentence goes on with the research result without describing the aim of the research. The research results are elaborately explained, and finally, the abstract ends with conclusion beginning from "The study indicated...".

One of the items to be analyzed in this study is finite verb tenses used in the abstracts. According to Oxford Advanced Learner's Dictionary of Current English, finite verb is a verb that agrees with a subject in number andperson (Hornby, 1980).Meanwhile, University College London (UCL) defines finite verbs as "Verbs which have the past or the present form are called FINITE verbs. Verbs in any other form (infinitive, $-i n g$, or -ed) are called nonfinite verbs. This means that verbs with tense are finite, and verbs without tense are nonfinite. The distinction between finite and nonfinite verbs is a very important one in grammar since it affects how verbs behave in sentences" (UCL, 2016). Unlike finite verbs which can function or fill the position of the predicate in a sentence, nonfinite verbs cannot. In a sentence construction, non-finite verbs which are also called verbals usually function as modifiers. However when combined with a modal, an auxiliary verb, nonfinite verbs can fill the position of the predicate. According to Huddleston\&Pullum (2005), finite verbs are verbs bound by temporal and spatial bounds while non-finite verbs are on the other way around. They further explain the way infinity has no temporal or spatial bounds induces the traditional notions 'finite' and 'non-finite' arose.

It can be summed up that the finite verbs are verbs that agree with number of subject and person as well as with the tenses or time signals.Finite verbs are the main verbs in a clause or sentence construction. Finite verbs indicate the existence of predicate of a clause or a sentence therefore, the role of these verbs is very essential. Without this kind of verbs, a string of words cannot be categorized as a clause or a sentence.

Based on the above description, auxiliary verbs can be categorized into finite verbs as they will have to agree 
with tenses of the clause or sentence. Even some of them agree with the number of subjects, such 'shall, will, has, and have.'

The data analysis shows that there are four types of tenses used in finite verbs i.e. Simple Present, Simple Past, Present, and Past Perfect tenses. The most frequently used tense is simple past tense (55 occurrences), followed by simple present tense (38 occurrences), and present perfect tense (11 occurrences). The least used tense is past perfect tense with only one occurrence. The distribution of the tenses in the abstracts is as follows: simple past tense is mostly used in Method and Result elements of the abstracts. The use of simple present tense is mostly used in the Introduction (21 occurrences), Recommendation (6 occurrences), Conclusion (5 occurrences), Objectives (4 occurrences), and Result (2 occurrences). Present perfect tense is mostly used in Introduction (8 occurrences).

The comprehensive abstract number 22 (sample no.22)by Perera et al., (2013) gives an example of three tenses in different elements of the abstract.

\section{2) Screening Coconut Cultivars for Tolerance to Infestation by the Coconut Mite, Aceriaguerreronis (Keifer) in Sri Lanka}

\author{
L. Perera ${ }^{1}$, S.R. Sarathchandra ${ }^{2}$ \\ and I.R. Wickramananda ${ }^{3}$
}

\begin{abstract}
The coconut mite (AceriaguerreronisKeifer) is a tiny pest which severely damages the nuts of the coconut palm (Cocosnucifera Linnaeus). At present, there is no appropriate control method for this pest in Sri Lanka. Field observations have revealed the difference in the severity of A.guerreronis mite infestation among selected and improved coconut cultivars in Sri Lanka. This difference has not been studied in depth and therefore the present study was conducted to investigate the levels of tolerance in selected and improved coconut cultivars and, if differences were demonstrated, to understand the mechanism behind the tolerance. A replicated trial in Thammenna Estate (TE) in Puttalam district in Sri Lanka, where the mite infestation was natural and severe, was selected for this study. The trial was planted in 1983 and consisted of two improved coconut cultivars; Sri Lanka Yellow Dwarf x Sri Lanka Tall (YDT) and Sri Lanka Green Dwarf x Sri Lanka Tall (GDT) and the selected Sri Lanka Tall cultivar (TT) which has, green (TTG) and russet coloured (TTR) forms. Population assessment of mites on immature nuts, damage initiation of the fourth bunch and harvest records were obtained. Further, characters that were thought to influence tolerance, such as nut shape as measured by ratio of length to breadth, the tightness of perianth to the nut surface and some changes in the affected tissues were also recorded. Yield data were collected perfect to estimate the crop loss due to coconut mite damage. The results revealed that out of the cultivars tested in this trial, YDT had the lowest incidence of mite colonization and the smallest
\end{abstract}

mite population size and symptom initiation compared to others. The distance between the perianth and nut surface, the least in YDT, is suggested as the most probable morphological feature that would impart tolerance to mite infestation.

\section{Keywords: Coconut, Cocosnucifera Linnaeus, tolerance, resistance, mite infestation, Aceriaguerreronis Keifer}

This comprehensive abstract uses simple present tense for the introduction part of the abstract"The coconut mite (AceriaguerreronisKeifer) is a tiny pest which severely damages the nuts of the coconut palm (Cocosnucifera Linnaeus)". At present, there is no appropriate control method for this pest in Sri Lanka. Present perfect tense was used to present previous study "Field observations have revealed the difference in the severity of A. guerreronis mite infestation among selected and improved coconut cultivars in Sri Lanka". Simple past tense is used to explain research objectives "...the present study was conducted to investigate the levels of tolerance in selected and improved coconut cultivars and, if differences were demonstrated, to understand the mechanism behind the tolerance. A replicated trial in Thammenna Estate (TE) in Puttalam district in Sri Lanka, where the mite infestation was natural and severe, was selected for this study". This kind of tense is also used to explain research methodology such as "The trial was planted in 1983 and consisted of two improved coconut cultivars; Sri Lanka Yellow Dwarf x Sri Lanka Tall (YDT) and Sri Lanka Green Dwarf x Sri Lanka Tall (GDT) and the selected Sri Lanka Tall cultivar (TT)...". Likewise, research result is presented using simple past too, for example, "The results revealed that out of the cultivars tested in this trial, YDT had the lowest incidence of mite colonization and the smallest mite population size and symptom initiation compared to others". Recommendation or suggestion which is the last element of the abstract is usually presented using simple present tense, for example "The distance between the perianth and nut surface, the least in YDT, is suggested as the most probable morphological feature that would impart tolerance to mite infestation."

The location distribution of tenses is as follows: it was found that out of 26 abstracts which have Introduction element, only one abstract (sample no 5) uses simple past. It means $96 \%$ Introduction element of the abstract usessimple present tense. Sometimes, present perfect tense is used in the introduction element of the abstract. All sample abstracts $(100 \%)$ which have Research Method element of the abstracts use simple past tense to explain research methodology. Simple past is also frequently used in the Result element of the abstracts in which $88 \%$ occurrences are in simple past, and each simple present and present perfect has $6 \%$ occurrences. All five sample abstracts (sample no.2, 6, 8, 9, 22) which have recommendations use simple present tense.

Unlike other languages such as Latin and Mongolian which have five voices, English only have two voices i.e. active and passive voice. Voice is defined as the relation between the subject or object of the action or state expressed by verb in the clause or sentence construction. In academic writing passive voice is preferred than active voice because it allows the writer to focus on person or event receiving or experiencing the action by placing it at the beginning of the clause or sentence. 
Based on the analysis, passive voices are used to express Research Methodology element of the abstract. All $(100 \%)$ sample abstracts analyzed in this study which contains research methodology use passive voice. It complies with academic writing theory which gives more emphasis on the use of passive voice than active voice. An example of research methodology using passive voice can be seen in sample abstract no. 2 "The experiment was laid down as Complete Randomized Block Design replicated three times". On the other hand Result element of the abstracts mostly uses active voice (82\%), the remaining $18 \%$ use passive voice. The all other elements of Introduction, Conclusion, and Recommendation use active voice with third person point of view. In academic writing, the third person point of view is also more recommended than the first person point of view.

\section{CONCLUSIONS}

Based on the completeness of abstract elements, the abstracts under this study can be divided into two categories i.e. indicative abstracts (21\%) and comprehensive/ informative abstracts (79\%). The completeness of informative/comprehensive abstracts varies. The most complete informative/comprehensive abstracts consisting of five elements account for $21 \%$, the comprehensive abstracts with four elements have the highest amount which is $41 \%$, and the comprehensive abstracts with three elements also have the least amount which is $17 \%$. It can be concluded that most comprehensive abstracts contain four elements which are background (introduction), objectives, methodology, and result.

Table 1 The Summary of Abstract Element Completeness

\begin{tabular}{|c|c|c|}
\hline Type of Abstacts & Abstract Number & Frequency \\
\hline $\begin{array}{l}\text { Informative abstracts } \\
\text { with } 5 \text { elements }\end{array}$ & $6,12,13,22,31,32,33$ & $7=(21 \%)$ \\
\hline $\begin{array}{l}\text { Informative abstracts } \\
\text { with } 4 \text { elements }\end{array}$ & $\begin{array}{l}3,8,11,14,17,18,19,20,2 \\
5,26,27,28,29,30\end{array}$ & $14=(41 \%)$ \\
\hline $\begin{array}{l}\text { Informative abstracts } \\
\text { with } 3 \text { elements }\end{array}$ & & $6=(17 \%)$ \\
\hline Indicative abstracts & $4,5,7,9,10,16,24$ & $7=(21 \%)$ \\
\hline Total & & $34=(100 \%)$ \\
\hline
\end{tabular}

The tenses of finite verbs commonly used in abstract writing consist of four tenses, they are Simple Present tense, Simple Past tense, Present Perfect, and Past Perfect tenses. The most frequently used tense is Simple Past tense with 55 occurrences, followed by Simple Present tense with 38 occurrences, and Present Perfect tense with 11 occurrences. The least used tense is Past Perfect tense with only one occurrence. The distribution of the tenses in the abstracts is as follows: simple past tense is mostly used in Method and Result elements of the abstracts. The use of simple present tense is mostly used in the Background or Introduction (21 occurrences), Recommendation (6 occurrences), Conclusion (5 occurrences), Objectives (4 occurrences), and Result (2 occurrences). Present perfect tense is mostly used in Introduction (8 occurrences), as seen in Table 1.
Table 2 The Summary of Finite Verb Tenses

\begin{tabular}{llc}
\hline Type of Tenses & \multicolumn{1}{c}{ Location } & Occurrence \\
\hline Simple Present & $\begin{array}{l}\text { In the elements of Introduction, } \\
\text { Objective, Result, Conclusion, and }\end{array}$ & 38 \\
Simple Past & $\begin{array}{l}\text { Recommendation } \\
\text { In the elements of Method and } \\
\text { Result }\end{array}$ & 55 \\
Present Perfect & $\begin{array}{l}\text { In the elements of Introduction/ } \\
\text { Background }\end{array}$ & 11 \\
Past Perfect & $\begin{array}{l}\text { In the elements of Introduction/ } \\
\text { Background }\end{array}$ & 1 \\
\hline Total & & 105 \\
\hline
\end{tabular}

Table 2 represents terms of voice of verbs in which both Active and Passive Voices are used in abstract writing. Passive voices are used to express Research Methodology element of the abstract. All sample abstracts in this study use passive voice to state research methodology.On the other hand, Result element of the abstracts mostly uses active voice $(82 \%)$, the remaining $18 \%$ use passive voice. The all other elements of Introduction, Conclusion, and Recommendation use active voice with third person point of view which is in compliance with academic writing theory.

\section{REFERENCES}

Bailey, S. (2011). Academic Writing: A handbook for international students. New York: Routledge.

Birmingham City University. (2015). Writing abstract. Retrieved January $6^{\text {th }}, 2015$ from http://library.bcu. ac.uk/learner/writingguides/1.28.htm.

Gallego, V.C., Gallego, M.C.E., \& Torre, I. (2013). Some biological and behavioral Studies of the Tetrastichussp. (Hymenoptera: Eulophidae), a Pupal Parasitoid of Brontispalongissima Gestro (Coleoptera: Chrysomelidae). CORD,29(2), 37-45.

Hamp-Lyons, L, \& Heasly, B. (2010). Study writing: A course in writing skills for academic purposes. Cambridge, UK: Cambridge University Press.

Hornby, A.S. (1980). Oxford Advanced Learner's Dictionary of Current English. New York: Oxford University Press .

Huddleston, R. \& Pullum, G. K. (2005). A student's Introduction to English Grammar. Cambridge, UK: Cambridge University Press.

Karouw, S., Suparmo, H. P., \& Utami , T. (2014). Fatty acids profile, oxidative and hydrolysis stability of virgin coconut oil and palm stearin based human milk fat analog. CORD, 30(2), 1-9

Limphapayom, W. (2013). Study on chocolate production from coconut oil and palm oil shortening. CORD 29(2), 13-18

Novarianto, H., Maskromo, I., Dinarti, D., \& Sudarsono. (2014). Production technology for kopyor coconut seednuts and seedlings in Indonesia. CORD, 30(2), $31-40$

Perera, L., Sarathchandra, S. R., \& Wickramananda, I. R. (2013). Screening coconut cultivars for tolerance to 
infestation by the coconut mite, Aceriaguerreronis (Keifer) in Sri Lanka.CORD, 29(1), 25-34

Pitkin, R.M., Branagan, M.A., Burmeister, L.F. (1999). Accuracy of data in abstracts of published research articles. The Journal of American Medical Association (JAMA), 281 (12), 1110-1111.

University College London.(2016).Finite Verbs and NonFinite Verbs. Retrieved March 24 $4^{\text {th }}, 2016$ fromhttp:// www.ucl.ac.uk/internet-grammar/verbs/finite.htm

University of North Carolina.(2014). Abstract. Retrieved from http://writingcenter.unc.edu/handouts/ abstracts/

Ware, M., \& Mabe, M. (2012). The STM (Scientific, Technical and Medical Publishers) report: An overview of scientific and scholarly journal publishing. The Hague, Netherlands: STM Publisher. 